\title{
Variabilidade genética de Sugarcane mosaic virus, causando mosaico em milho no Brasil
}

\author{
Marcos Cesar Gonçalves( ${ }^{(1)}$, Diogo Manzano Galdeano(1), Ivan de Godoy Maia ${ }^{(2)}$ e César Martins Chagas(1)
}

(1)Instituto Biológico, Centro de Pesquisa e Desenvolvimento em Sanidade Vegetal, Avenida Conselheiro Rodrigues Alves 1252, CEP $04014-002$ São Paulo, SP. E-mail: mcgon@biologico.sp.gov.br, diogo_manzano@hotmail.com, cesar_orion@yahoo.com (2)Universidade Estadual Paulista, Campus de Botucatu, Instituto de Biociências, Departamento de Genética, CEP 18618-000 Botucatu, SP. E-mail: igmaia@ibb.unesp.br

Resumo - O objetivo deste trabalho foi caracterizar biológica e molecularmente três isolados de Sugarcane mosaic virus (SCMV) de lavouras de milho, analisá-los filogeneticamente e discriminar polimorfismos do genoma. Plantas com sintomas de mosaico e nanismo foram coletadas em lavouras de milho, no Estado de São Paulo e no Município de Rio Verde, GO, e seus extratos foliares foram inoculados em plantas indicadoras e submetidos à análise sorológica com antissoros contra o SCMV, contra o Maize dwarf mosaic virus (MDMV) e contra o Johnsongrass mosaic virus (JGMV). Mudas de sorgo 'Rio' e 'TX 2786' apresentaram sintomas de mosaico após a inoculação dos três isolados, e o DAS-ELISA confirmou a infecção pelo SCMV. O RNA total foi extraído e usado para amplificação por transcriptase reversa seguida de reação em cadeia de polimerase (RT-PCR). Fragmentos específicos foram amplificados, submetidos à análise por polimorfismo de comprimento de fragmento de restrição (RFLP) e sequenciados. Foi possível discriminar os genótipos de SCMV isolados de milho de outros isolados brasileiros do vírus. Alinhamentos múltiplos e análises dos perfis filogenéticos corroboram esses dados e mostram diversidade nas sequências de nucleotídeos que codificam para a proteína capsidial, o que explica o agrupamento separado desses isolados e sugere sua classificação como estirpes distintas, em lugar de simples isolados geográficos.

Termos para indexação: Potyviridae, Zea mays, mosaico comum do milho, RFLP, RT-PCR.

\section{Genetic variability of Sugarcane mosaic virus causing maize mosaic in Brazil}

\begin{abstract}
The objective of this work was to characterize biologically and molecularly three Sugarcane mosaic virus (SCMV) isolates from maize crops in Brazil, to analyze them phylogenetically and to discriminate genome polymorphisms. Plants with mosaic and stunting symptons were collected from maize crops in the state of São Paulo and in Rio Verde county, GO, Brazil; their foliar extracts were inoculated in indicator plants and subjected to serological analysis with antisera to SCMV, Maize dwarf mosaic virus (MDMV) and Johnsongrass mosaic virus (JGMV). Sorghum 'Rio' and 'TX 2786' seedlings showed mosaic symptons after inoculation of the three isolates, and DAS-ELISA confirmed infection by SCMV in these plants. Total RNA was extracted from the infected leaves and was used as template for reverse transcriptase polymerase chain reaction (RT-PCR). Specific fragments were amplified, subjected to restriction fragment length polymorphism (RFLP) analysis and sequenced. It was possible to discriminate the SCMV maize isolates from other Brazilian isolates of the virus. Multiple alignments and phylogenetic profile analyses corroborate these data and show diversity in the sequence of nucleotides that code for capsidal protein, what explains the distinct clustering of these isolates, suggesting that they should be ranked as distinct SCMV strains rather than geographical isolates.
\end{abstract}

Index terms: Potyviridae, Zea mays, maize common mosaic, RFLP, RT-PCR.

\section{Introdução}

O mosaico é uma das principais viroses incidentes na cultura do milho (Zea mays L.) no Brasil. Mundialmente, a doença pode ser causada por seis espécies de vírus que infectam o milho e constituem um subgrupo viral: Sugarcane mosaic virus (SCMV), espécie que dá nome ao subgrupo; Maize dwarf mosaic virus (MDMV); Johnsongrass mosaic virus (JGMV); Sorghum mosaic virus (SrMV) (Lesemann et al., 1992; Shukla et al., 1992); Zea mosaic virus (ZeMV) (Seifers et al., 2000); e Pennisetum mosaic virus (PenMV), espécie recentemente sugerida como um novo membro do subgrupo (Deng et al., 2008). Também faz parte

Pesq. agropec. bras., Brasília, v.46, n.4, p.362-369, abr. 2011 
deste subgrupo o Sugarcane streak mosaic virus (SCSMV), espécie viral que não infecta o milho (Hema et al., 2002). No Brasil, apenas o SCMV e o MDMV são descritos em infecções naturais na cultura do milho (Almeida et al., 2000; Gonçalves et al., 2007a).

Os vírus do subgrupo do SCMV e suas diversas estirpes pertencem ao gênero Potyvirus, família Potyviridae (Shukla et al., 1994; Berger et al., 2005). Os dados de sequência nucleotídica da proteína capsidial dos Potyvirus podem ser usados para prover uma classificação hierárquica dentro da família Potyviridae (Chen et al., 2002; Adams et al., 2005; Viswanathan et al., 2009; Wang et al., 2010). Há uma distribuição bimodal entre 17 estirpes, pertencentes a oito espécies de Potyvirus. Espécies distintas do gênero apresentam identidades de sequência que variam de 38 a $71 \%$ ou de 75 a $89 \%$, enquanto estirpes de um mesmo vírus exibem de 90 a $99 \%$ de identidade. Por sua vez, a região C-terminal do gene Nib, no genoma viral, é altamente conservada entre os Potyvirus (Shukla et al., 1994; Perera et al., 2009), o que confere a possibilidade de desenho de oligonucleotídeos degenerados universais para Potyvirus a partir das sequências conhecidas.

Os Potyvirus são transmitidos por várias espécies de afídeos, com maior eficiência por Rhopalosiphum maidis (Fitch) e Schizaphis graminum (Rondani) (Pirone, 1972; Shukla et al., 1994), cuja incidência é comum no Brasil. Os sintomas de infecção em milho variam conforme a espécie e estirpe do vírus, bem como com a cultivar de milho (Gonçalves et al., 2007a). Os programas de melhoramento genético de milho realizam a avaliação de novas cultivares e híbridos quanto à tolerância ao mosaico (Schuelter et al., 2003); porém, não há recomendação de cultivares resistentes à doença. A adoção de cultivares tolerantes evita que o mosaico ocasione grandes perdas na cultura.

No Brasil, não há relatos de grande impacto econômico desse vírus nos últimos anos. Entretanto, o SCMV pode ocorrer em infecções mistas com o Maize rayado fino virus (MRFV) e causar danos mais severos e perdas de maior proporção à cultura (Gonçalves et al., 2007a). Outro aspecto a ser considerado é o de que o SCMV também incide sobre outras poáceas cultivadas, entre as quais a cana-de-açúcar (Sacharum spp.) e o sorgo [Sorghum bicolor (L.) Moench] (Espejel et al., 2006), além de atacar diversas espécies da vegetação espontânea, como os capins massambará (Sorghum halepense L.) e colonião (Panicum maximum Jacq.) (Pirone, 1972).
Em razão do grande aumento na área plantada de cana-de-açúcar no país, nos últimos anos, e do advento do cultivo de milho na safrinha (milho semeado entre janeiro e março), a incidência do mosaico tem aumentado no campo (Dudienas et al., 1997; Fernandes \& Oliveira, 1997; Gonçalves et al., 2007b). Assim, amplia-se a possibilidade de que novas estirpes do SCMV estejam se disseminando no país, o que merece um estudo mais detalhado da variabilidade do vírus. Informações sobre este assunto são pouco difundidas no Brasil, porém são essenciais para o sucesso do melhoramento genético do milho quanto à resistência ao mosaico-comum.

Nos anos de 2006 e 2007, foram observadas várias lavouras de milho atacadas com o mosaico-comum do milho, especialmente no Estado de São Paulo e região do Município de Rio Verde, GO, conforme Gonçalves et al. (2007b).

O objetivo deste trabalho foi caracterizar biológica e molecularmente três isolados do SCMV, de lavouras de milho, analisá-los filogeneticamente e discriminar polimorfismos do genoma, em comparação a diversos outros isolados do vírus do Brasil e exterior.

\section{Material e Métodos}

Amostras de cultivares de milho com sintomas de mosaico foram coletadas em campos experimentais e comerciais nos municípios de Campinas e Santo Antônio da Posse, no Estado de São Paulo, e no Município de Rio Verde, Estado de Goiás, nos anos de 2006 e 2007. Os isolados virais foram identificados; o material foliar coletado foi utilizado para inoculações, e o restante separado em alíquotas para armazenamento a $-20^{\circ} \mathrm{C}$. Os isolados receberam os nomes de SCMV-CAMP, SCMV-STAP e SCMV-RV, de acordo com as letras iniciais dos municípios de coleta.

Para a caracterização biológica, os isolados virais foram inoculados nas hospedeiras diferenciais de sorgo (Sorghum bicolor) - 'Rio' e 'TX 2786' - e aveia (Avena sativa L.) (Shukla et al., 1994; Brunt et al., 1997). As inoculações foram realizadas com alíquotas de folhas das plantas infectadas, trituradas em nitrogênio líquido e diluídas à razão $1: 10$, em tampão fosfato

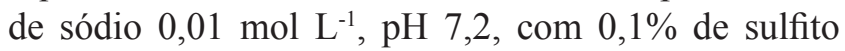
de sódio. Dez plantas de cada espécie e cultivar das plantas indicadoras foram infectadas no estádio de oito dias após a emergência, e uma planta adicional foi deixada como controle, sem inoculação. Todas 
as plantas foram mantidas em casas de vegetação, sem controle de temperatura e umidade, com tela de proteção anti-afídeos, e os sintomas foram monitorados, semanalmente, durante três meses.

Os isolados, coletados da parte aérea de plantas de milho com sintomas de mosaico, foram submetidos à análise por DAS-ELISA, com antissoros AGDIA (AGDIA Inc., Elkhart, Indiana, EUA) para as espécies SCMV, JGMV e MDMV do subgrupo do SCMV, tendo-se utilizado controles positivos e negativos para cada espécie de vírus, adquiridos da mesma empresa. O procedimento para as análises e os tampões utilizados seguiram as recomendações do fabricante.

Amostras de folhas infectadas com os três isolados de milho foram analisadas por microscopia eletrônica de transmissão. Para observações em contraste negativo, fragmentos de folhas com sintomas foram macerados em tampão fosfato $0,1 \mathrm{~mol} \mathrm{~L}^{-1}, \mathrm{pH} 7,0$. Telas revestidas com filme de colódio, reforçado com carvão, foram deixadas por $5 \mathrm{~min}$ sobre uma gota do extrato obtido e lavadas com água destilada, e as preparações foram contrastadas em acetato de uranila a 2\%. Para observações in situ, fragmentos foliares do mesmo material foram fixados por 12 horas a $4^{\circ} \mathrm{C}$ em glutaraldeído a 2,5\% em tampão fosfato $0,1 \mathrm{~mol} \mathrm{~L}^{-1}$, pH 6,8 , pós-fixados em tetróxido de ósmio a $1 \%$ no mesmo tampão, contrastados em acetato de uranila a $2 \%$ por 6 horas, desidratados e incluídos em resina Spurr. Secções ultrafinas desse material foram obtidas em ultramicrótomo LKB III (LKB Produkter AB, Bromma, Suécia), e contrastadas com acetato de uranila a $2 \%$ e citrato de chumbo Reynolds. As observações foram efetuadas em microscópio eletrônico de transmissão (EM208, Philips, Eindhoven, Holanda).

O RNA total das folhas infectadas foi extraído com o reagente Trizol (Invitrogen, Carlsbad, CA, EUA). Um oligonucleotídeo de 17-mer, ancorado na sua extremidade 3' $\left(\mathrm{dT}_{17} \mathrm{~V}\right)$, foi utilizado para a obtenção dos cDNAs. As reações de transcrição reversa (RT) foram realizadas com o kit cMaster Rtplus (EppendorfNetheler, Hamburg, Alemanha), tendo-se aplicado $2 \mu \mathrm{g}$ de RNA total extraído das plantas infectadas, em combinação com $5 \mu \mathrm{mol} \mathrm{L}^{-1}$ do oligonucleotídeo $\mathrm{dT}_{17} \mathrm{~V}$, previamente incubados a $70^{\circ} \mathrm{C}$ por $10 \mathrm{~min}$. Os oligonucleotídeos senso, SCMVF4 (Alegria et al., 2003) e SrMVF3 (Yang \& Mirkov, 1997), e os oligonucleotídeos anti-senso, SCMVR3 e SrMVF3 (Yang \& Mirkov, 1997), foram usados para amplificar regiões do genoma correspondentes à capa proteica (CP) das espécies SCMV e SrMV, respectivamente. O oligonucleotídeo senso GARGCATGGGGATA (SCMVNI2), localizado na região C-terminal da proteína de inclusão $\mathrm{NIb}$, desenvolvido no presente trabalho a partir do alinhamento de sequências de nucleotídeos correspondentes de diversas espécies e estirpes do subgrupo do SCMV, também foi utilizado nas reações. $\mathrm{O}$ cDNA proveniente da reação de RT foi amplificado com três combinações de oligonucleotídeos: $5 \mu \mathrm{mol} \mathrm{L}{ }^{-1}$ do oligonucleotídeo degenerado SCMVF4 e $1 \mu \mathrm{mol} \mathrm{L}^{-1}$ do oligonucleotídeo SCMVF3; $1 \mu \mathrm{mol} \mathrm{L}{ }^{-1}$ dos oligonucleotídeos SrMVF3 e SrMVR3; $5 \mu \mathrm{mol} \mathrm{L}{ }^{-1}$ do oligonucleotídeo degenerado SCMVNI2 e $1 \mu \mathrm{mol} \mathrm{L}^{-1}$ do oligonucleotídeo SCMVR3. As reações de PCR foram feitas com $2 \mu \mathrm{L}$ do produto da RT por reação, conforme as instruções do kit cMaster Rtplus (Eppendorf, Westbury, New York, EUA). As amostras foram levadas para um termociclador PTC-200, (MJ-Research, Waltham, MA, EUA) onde, após a desnaturação inicial a $94^{\circ} \mathrm{C}$ por $3 \mathrm{~min}$, a amplificação foi feita com 35 ciclos de $94^{\circ} \mathrm{C}$ por $1 \mathrm{~min}, 54^{\circ} \mathrm{C}$ por $2 \mathrm{~min}, 72^{\circ} \mathrm{C}$ por $3 \mathrm{~min}$, seguidos por uma extensão final a $72^{\circ} \mathrm{C}$ por $10 \mathrm{~min}$. Os produtos de RT-PCR foram analisados por eletroforese em gel de agarose a 1,2\%, corados com brometo de etídeo e observados sob luz UV.

Após a análise das sequências de nucleotídeos da capa proteica, das diferentes espécies componentes do complexo viral do SCMV disponíveis no GenBank (National Center for Biotechnology Information, 2011b), foram selecionadas as enzimas de restrição Hpal e Dral para as análises por RFLP. Os produtos de RT-PCR, obtidos com os oligonucleotídeos específicos, foram precipitados com acetato de sódio $0,3 \mathrm{~mol} \mathrm{~L}^{-1} \mathrm{e}$ 2,5 volumes de etanol. Os precipitados foram lavados com etanol a 70\%, ressuspendidos em água deionizada purificada (Milli-Q) e submetidos à digestão enzimática por cerca de 2 horas a $37,5^{\circ} \mathrm{C}$. Os produtos da digestão foram analisados por eletroforese em gel de agarose a $2 \%$, corados com brometo de etídeo e observados sob luz UV (Sambrook et al., 1989).

As bandas selecionadas foram recortadas do gel e pesadas para purificação do DNA com o kit Rapid Gel Extraction GIBCO, BRL, (Life Technologies, New York, NY, EUA). Os fragmentos de DNA foram clonados por meio do pGEM-T Easy Vector System (Promega, Madison, WI, EUA) e pCR2.1-Topo 
(Invitrogen, Carlsbad, CA, EUA). Os plasmídeos recombinantes foram analisados a partir de insertos do tamanho esperado, e amplificados em Escherichia coli $\mathrm{DH} 5 \alpha$. Após a seleção dos clones recombinantes em meio com antibiótico, a presença dos fragmentos clonados nos respectivos vetores foi confirmada por digestão com a enzima de restrição EcoRI, e posterior eletroforese em gel de agarose a $1 \%$, corado com brometo de etídeo e observado sob luz UV. Os fragmentos de DNA eluídos foram precipitados com etanol absoluto e acetato de sódio $3 \mathrm{~mol} \mathrm{~L}^{-1}$, $\mathrm{pH} 5,1$. Os sedimentos obtidos foram ressuspendidos em tampão TE pH 8,0 e purificados em coluna Qiaquick (Qiagen, Valencia, CA, EUA). As sequências de nucleotídeos foram determinadas com o kit Big Dye (Applied Biosystems Inc., Carlsbad, CA, EUA) segundo protocolo do fabricante, em um sequenciador automático modelo ABI3100 (Applied Biosystems Inc., Carlsbad, CA, EUA). Foram realizadas três reações de sequenciamento, com cada oligonucleotídeo, para a confirmação das sequências obtidas.

As sequências de nucleotídeos e as deduzidas em aminoácidos resultantes foram analisadas e alinhadas com o programa Bio Edit Sequence Alignment Editor (Hall, 1999), e os consensos submetidos ao algoritmo BLAST do NCBI (National Center for Biotechnology Information, 2011a), para comparação com as sequências homólogas depositadas no GenBank. Alinhamentos múltiplos foram realizados com o programa ClustalW (Thompson et al., 1994), e o grau de identidade de nucleotídeos foi determinado com o BioEdit.

As sequências deduzidas de aminoácidos da capa proteica dos três isolados de milho e as de outros membros do subgrupo do SCMV foram utilizadas para as análises filogenéticas. A árvore filogenética foi construída pelo método de "neighbor-joining", com o programa PAUP 4.0b8 (Sinauer Associates Inc. Publishers, Sunderland, MA, EUA), e a robustez dos dados foi obtida com 2000 reamostragens de "bootstraps".

\section{Resultados e Discussão}

A caracterização biológica revelou que os três isolados de milho pertencem à espécie SCMV, em razão dos sintomas característicos apresentados pelas hospedeiras diferenciais. Os três isolados inoculados produziram sintomas de mosaico, com diferentes intensidades, em sorgo 'Rio' e 'TX 2786'. As plantas de aveia infectadas com os isolados selecionados não apresentaram sintomas de infecção. Inicialmente, a infecção e os sintomas de mosaico em sorgo 'Rio' indicaram tratar-se de isolados do subgrupo do SCMV, possivelmente uma das espécies, SCMV, MDMV, SrMV ou JGMV, as quais infectam naturalmente o milho. A ausência de infecção em aveia eliminou a possibilidade de infecção pelo JGMV. A infecção no sorgo 'TX2786' descartou a possibilidade de tratar-se da espécie SrMV, que não infecta esta cultivar (Tosic et al., 1990). Os resultados de DAS-ELISA também excluíram a possibilidade de infecção pelas espécies MDMV e JGMV, ao mesmo tempo que confirmaram a infecção pelo SCMV. As leituras de absorbância em DAS-ELISA foram feitas a $405 \mathrm{~nm}$ e as amostras que tiveram média dos valores de absorbância, de três réplicas, superior a três vezes a média do controle negativo, foram consideradas positivas. Os isolados analisados reagiram positivamente apenas quanto ao SCMV, e confirmaram os resultados das indexações biológicas.

É importante observar que, apesar de a ocorrência da estirpe MDMV-B ter sido relatada recentemente no Brasil (Almeida et al., 2000), houve uma reclassificação das estirpes de SCMV e MDMV com base nos estudos sorológicos com anticorpos específicos de vírus direcionados à região $\mathrm{N}$-terminal da proteína capsidial (Shukla et al., 1994). Esta estirpe passou a ser considerada como pertencente ao SCMV, dado confirmado posteriormente pelo sequenciamento do seu RNA viral (Yang \& Mirkov, 1997). Os resultados relatados no presente trabalho reafirmam a constatação feita por Gonçalves et al. (2007b) de que o agente causal predominante do mosaico em poáceas no Brasil é o SCMV, e a espécie MDMV não ocorre no país.

As amostras de extratos foliares apresentaram partículas virais alongadas e flexuosas, com tamanho entre 756 e $801 \mathrm{~nm}$. As secções ultrafinas mostraram partículas virais no citoplasma semelhantes às observadas nos contrastes negativos, além de inclusões citoplasmáticas típicas de Potyviridae, entre elas agregados lamelares, cata-ventos e tubos ou "scrolls" (Figura 1). A ocorrência simultânea dos três tipos de inclusões cilíndricas citoplasmáticas é característica de infecção por SCMV, uma vez que as demais espécies do subgrupo induzem apenas a formação de cata-ventos e "scrolls" (Lesemann et al., 1992). Estes resultados são 
corroborados pelos relatados na indexação biológica e na análise sorológica dos isolados.

A análise eletroforética dos produtos de RT-PCR mostrou a presença de fragmentos específicos de 888 pb para os isolados testados, amplificados com o par de oligonucleotídeos SCMVF4 e SCMVR3. Não houve amplificação com o par de oligonucleotídeos SrMVF3 e SrMVR3 (Figura 2). A combinação dos oligonucleotídeos SCMVNI2 e SCMVR3 amplificou fragmentos de $1.501 \mathrm{pb}$ que cobriam a proteína capsidial e parte da região C-terminal da proteína de inclusão NIb (Figura 3). A amplificação de fragmentos específicos somente com os oligonucleotídeos para o SCMV, aliada aos dados de sequenciamento, confirmaram que os isolados pertencem à espécie SCMV, o que descartou a possibilidade da presença da espécie SrMV, sem relatos no Brasil até o momento.

Os fragmentos de $888 \mathrm{pb}$ amplificados a partir dos três isolados de milho, correspondentes à capa proteica, foram submetidos à digestão com as enzimas Hpal e Dral. A digestão enzimática também foi realizada com fragmentos do mesmo tamanho, amplificados com o mesmo par de oligonucleotídeos, provenientes de outros isolados obtidos de milho e de cana-de-açúcar (Gonçalves et al., 2007a; 2007b). Os produtos de amplificação obtidos para os três isolados do milho não sofreram restrição enzimática com as endonucleases testadas (Figura 4). Os demais isolados de cana-de-açúcar

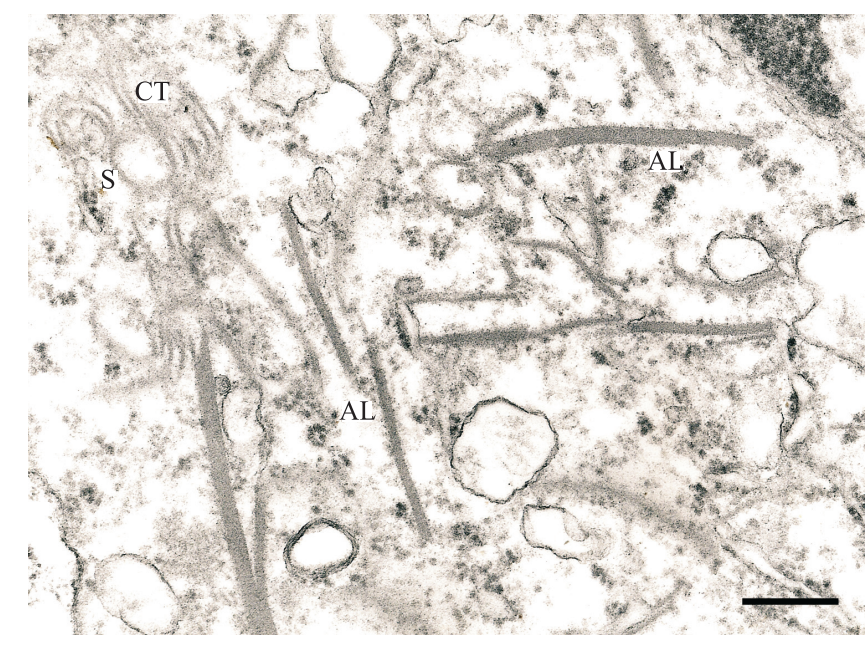

Figura1. Micrografia eletrônica de secções ultrafinas de parênquima foliar de milho infectado com o isolado SCMV Campinas, com inclusões cilíndricas citoplasmáticas: agregados laminares (AL), "scrolls" (S) e cata-ventos (CT). Barra de escala $=300 \mathrm{~nm}$. e milho produziram fragmentos de aproximadamente 550 e 340 nucleotídeos, quando tratados com a enzima Hpal, o que mostra polimorfismo entre os dois grupos de isolados (Figura 5). Estes resultados permitiram separar os três isolados de milho dos outros analisados. O perfil eletroforético de restrição encontrado para os demais isolados de cana-de-açúcar e milho está de acordo com o esperado para isolados do SCMV e segue o mesmo padrão descrito por Yang \& Mirkov (1997), o que possibilita a confirmação da infecção por essa espécie.

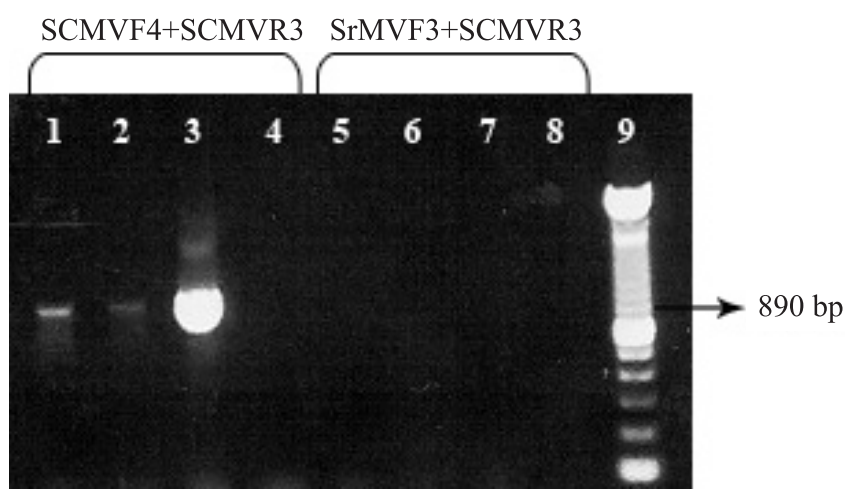

Figura 2. Análise eletroforética dos produtos amplificados por RT-PCR, com os pares de oligonucleotídeos SCMVF4, SCMVR3 e SrMVF3, SrMVR3, a partir de RNA total extraído de folhas de milho infectadas. Colunas: 1, milho de Rio Verde; 2, milho de Santo Antônio; 3, milho de Campinas; 4, controle negativo (sorgo sadio); 9, marcador de massa molecular, DNA 100 pb.

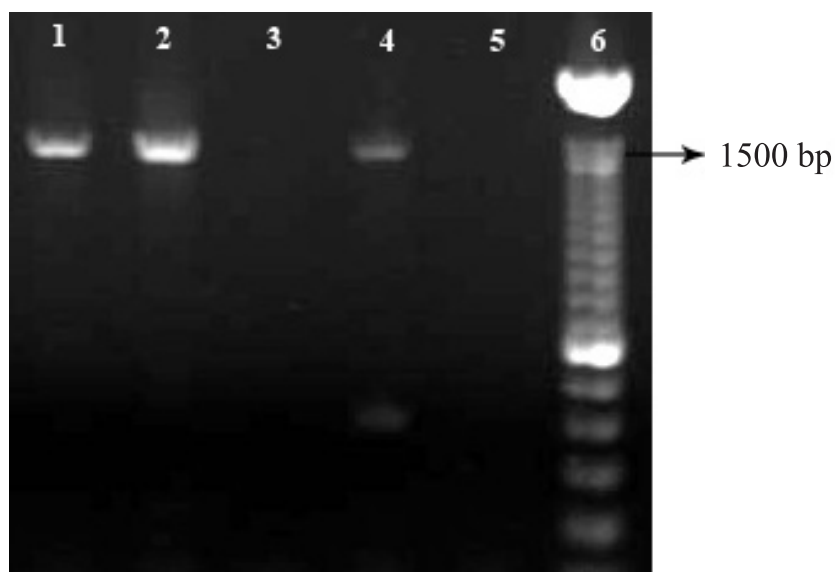

Figura 3. Análise eletroforética dos produtos amplificados por RT-PCR, com os oligonucleotídeos SCMVNI2 e SCMVR3, a partir de RNA total extraído de folhas de milho infectadas. Colunas: 1, milho de Campinas; 2, milho de Santo Antônio; 3, vazio; 4, milho de Rio Verde; 5, sorgo sadio; 6, marcador de massa molecular, DNA 100 pb. 
As sequências de nucleotídeos, obtidas a partir dos fragmentos amplificados com o par de oligonucleotídeos SCMVF4 e SCMVR3, que compreendem a proteína capsidial, apresentaram alguns nucleotídeos indefinidos na porção N-terminal da proteína. Por este motivo, nas reações de sequenciamento que se sucederam, foram usados os fragmentos de $1.501 \mathrm{pb}$, amplificados com os oligonucleotídeos SCMVNI2 e SCMVR3, o que produziu sequências de maior confiabilidade nessa região. As sequências de nucleotídeos codificadores da proteína capsidial, e parte da replicase (gene NIb) dos isolados SCMV-CAMP, SCMV-STAP e SCMV-RV, encontram-se sob os respectivos números de acesso no GenBank: HQ342698, HQ439439 e HQ439440.

Quando comparadas às sequências de nucleotídeos dos outros isolados brasileiros e às de maior identidade depositadas no GenBank, a sequência de nucleotídeos da região N-terminal da proteína capsidial dos isolados de milho apresentaram a maior variabilidade (Figura 6). De acordo com Adams et al. (2005), Zhong et al. (2005) e Wang et al. (2010), a região N-terminal da capa proteica apresenta maior variabilidade de sequências entre os membros de Potyviridae e, muitas vezes, determina a distinção de estirpes e espécies dentro da família. Uma possível explicação para essa diversidade é a duplicação de motivos peptídicos curtos, como a relatada para estirpes do SCMV e SrMV (Yang \& Mirkov, 1997).

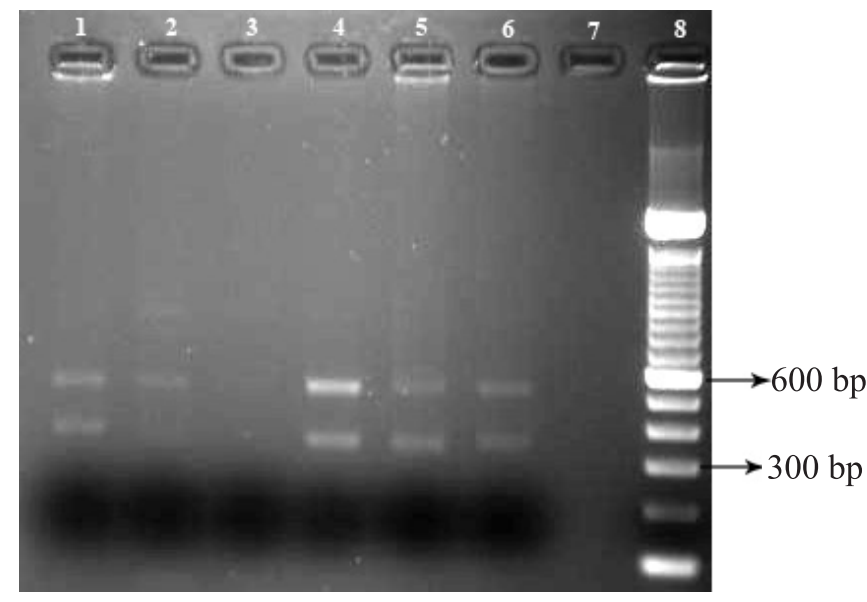

Figura 4. Análise de polimorfismos de comprimento de fragmentos, com uso das enzimas de restrição Hpal e Dral, dos produtos de RT-PCR de isolados virais de cana-de-açúcar e milho. Colunas: 1, cana Jaú; 2, milho de São José Bela Vista; 3, milho de Ribeirão Preto; 4, cana de Novo Horizonte; 5, cana de Jussara; 6, cana de Serrana; 7, vazio; 8, marcador de massa molecular, DNA de 100 bp.
A maior percentagem de identidade das sequências de nucleotídeos da capa proteica dos três isolados de milho ocorreu com outros nove isolados brasileiros do SCMV, depositados no GenBank. A percentagem de identidade variou de 91 a $93 \%$, com os isolados BR01, BR02, BR06, BR08, BR09, BR10, BR11, BR13 e BR14, sob os números de acesso DQ315489, DQ315490, DQ315491, DQ315492, DQ315493, DQ315494, DQ315495, DQ315496 e DQ315497, respectivamente (Figura 6).

As sequências deduzidas de aminoácidos da capa proteica destes isolados, e as de outros membros do subgrupo do SCMV e do gênero Potyvirus foram utilizadas para a análise filogenética dos isolados. O filograma obtido ilustra a posição dos três isolados de milho, em relação aos demais isolados brasileiros do SCMV de milho e cana-de-açúcar, aos isolados de diferentes regiões geográficas, e às espécies MDMV, SrMV e JGMV (Figura 6). A análise filogenética realizada permitiu a separação de quatro grupos monofiléticos distintos de isolados do SCMV. São claramentevisíveis três grupos: um formado por isolados de cana-de-açúcar e milho provenientes do Brasil e da Austrália; um formado pelos isolados brasileiros previamente mencionados, BR01, BR02, BR06, BR08, BR09, BR10, BR11, BR13, provenientes de diferentes localidades do Brasil; e um terceiro formado pelos três isolados de milho SCMV-CAMP, SCMV-STAP, SCMV-RV e o isolado BR14, sem referências precisas sobre sua origem. Ainda é possível visualizar a

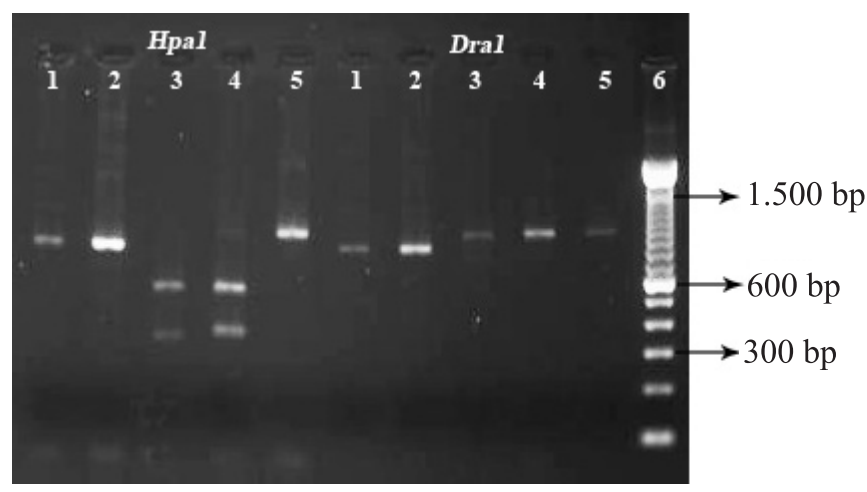

Figura 5. Análise de polimorfismos de comprimento de fragmentos, com uso das enzimas de restrição Hpal e Dral, dos produtos de RT-PCR de isolados virais de cana-de-açúcar e milho. Colunas: 1, Milho de Santo Antônio da Posse; 2, milho de Campinas; 3, cana de Ribeirão Preto; 4, cana de Buritizal; 5, milho de Rio Verde; 6, marcador de massa molecular, DNA de 100 bp. 


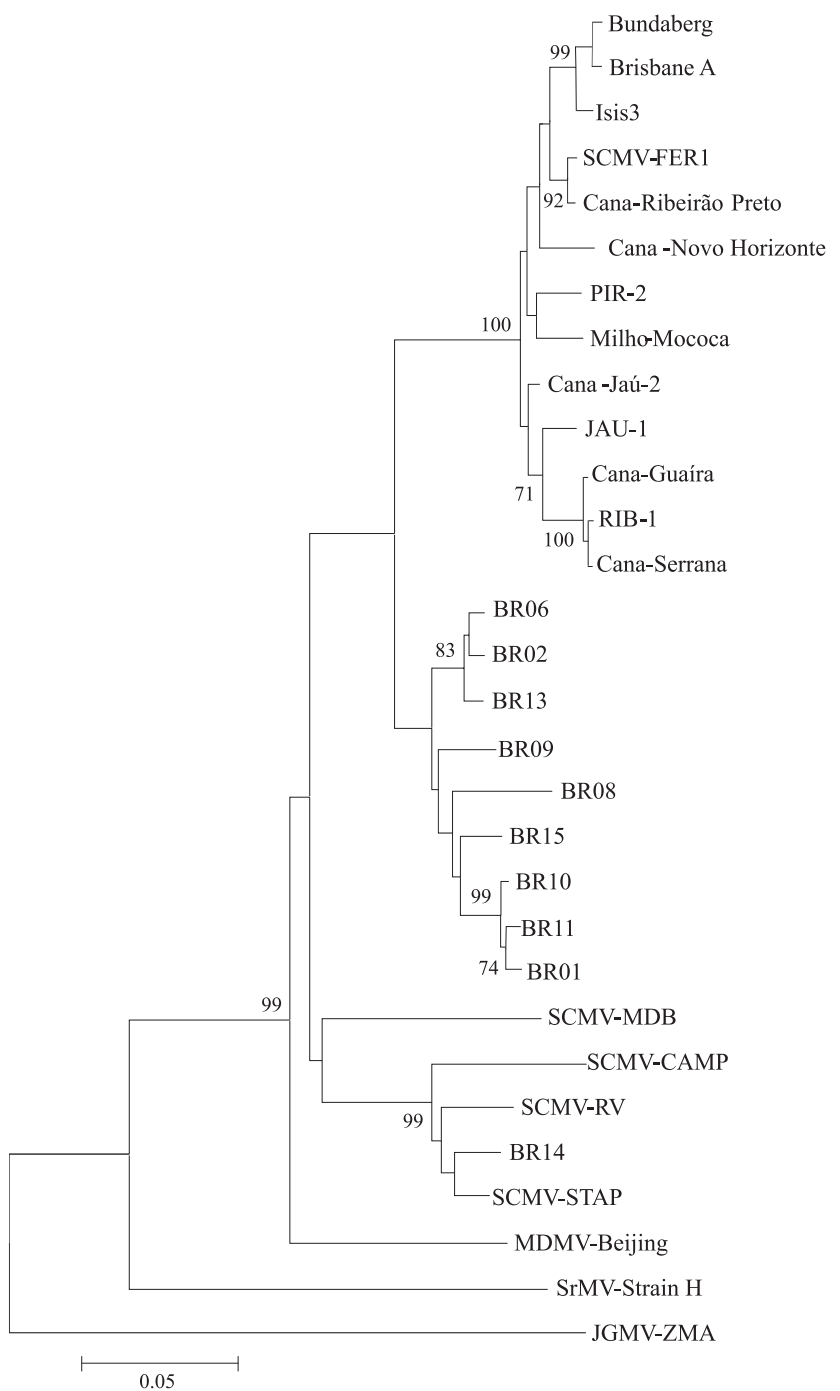

Figura 6. Análise filogenética por "neighbor-joining", com 2.000 "bootstraps", tendo-se empregado as sequências deduzidas de aminoácidos da capa proteica de diferentes isolados do subgrupo do SCMV e espécies de Potyvirus relacionadas. A percentagem de réplicas de "bootstrap" observada é indicada para cada ramo. Abreviações e respectivos números de acesso no GenBank: SCMV-Bundaberg (AAC17482); SCMV-Brisbane Strain A (CAC81986); SCMV Isis-3 (AF006728); SCMV-FER1 (AY819719); Cana de Ribeirão Preto (não registrado); Cana de Novo Horizonte (não registrado); SCMV-PIR-2 (AY819718); Milho de Mococa (não registrado); Cana de Jaú-2 (não registrado); SCMV-JAU-1 (AY819717); Cana de Guaíra (não registrado); SCMV-RIB-1 (AY819716); Cana de Serrana (não registrado); BR01 (DQ315489); e, BR02 (DQ315490); BR06 (DQ315491); BR08 (DQ315492); BR09 (DQ315493); BR10 (DQ315494); BR11 (DQ315495); BR13 (DQ315496); BR14 (DQ315497); SCMV-MDB (D00949); SCMV-CAMP (HQ342698); SCMV-STAP (HQ439439); SCMV-RV (HQ439440); MDMV-Beijing (CAA04929); SrMV-strain H (CAC84434); JGMV-ZMA (NP619668). separação do SCMV-MDB em um único grupo que, apesar de classificado como um isolado do SCMV, foi sugerido como uma nova espécie do subgrupo (Yang \& Mirkov, 1997). É interessante observar que os isolados de milho estudados no presente trabalho agrupam-se apenas com o isolado brasileiro BR14, e constituem, provavelmente, uma única estirpe viral, apesar da origem geográfica diversa desses isolados.

\section{Conclusões}

1. Os isolados de Sugarcane mosaic virus obtidos de lavouras de milho em Campinas e Santo Antônio da Posse, Estado de São Paulo, e no Município de Rio Verde, Estado de Goiás, constituem uma nova estirpe do SCMV no Brasil.

2. Os isolados brasileiros de Sugarcane mosaic virus BR01, BR02, BR06, BR08, BR09, BR10, BR11 e BR13 constituem uma estirpe distinta dos isolados SCMV avaliados no presente trabalho.

\section{Agradecimentos}

À Fundação de Amparo à Pesquisa do Estado de São Paulo, pelo apoio financeiro . À Dra. Gisèle Maria Fantin, do Instituto Biológico, pelo fornecimento de amostras de milho infectadas do Estado de Goiás.

\section{Referências}

ADAMS, M.J.; ANTONIW, J.F.; FAUQUET, C.M. Molecular criteria for genus and species discrimination within the family Potyviridae. Archives of Virology, v.150, p.459-479, 2005.

ALEGRIA, O.M.; ROYER, M.; BOUSALEM, M.; CHATENET, M.; PETERSCHMITT, M.; GIRARD, J.-C.; ROTT, P. Genetic diversity in the coat protein coding region of eighty-six sucarcane mosaic virus isolates from eight countries, particularly from Cameroon and Congo. Archives of Virology, v.148, p.357-372, 2003.

ALMEIDA, A.C.L.; OLIVEIRA, E.; RESENDE, R. Detecção de vírus por RT-PCR, hibridação "dot-blot" e dot-ELISA em milho com mosaico-comum. Fitopatologia Brasileira, v.25, p.168-170, 2000.

BERGER, P.H.; ADAMS, M.J.; BARNETT, O.W.; BRUNT, A.A.; HAMMOND, J.; HILL, J.H.; JORDAN, R.L.; KASHIWAZAKI, S.; RYBICKI, E.; SPENCE, N.; STENGER, D.C.; OHKI, S.T.; UYEDA, I.; ZAAYEN, A. van; VALKONEN, J.; VETTEN, H.J. Family Potyviridae. In: FAUQUET, C.M.; MAYO, M.A.; MANILOFF, J.; DESSELBERGER, U.; BALL, L.A (Ed.). Virus taxonomy. London: Academic Press, 2005. p.819-841.

BRUNT, A.A.; CRATBREE, K.; DALLWITZ, M.J.; GIBBS, A.J.; WATSON, L. Viruses of plants. Wallingford: CAB International, 1997. 
CHEN, J.; CHEN, J.; ADAMS, M.J. Characterisation of potyviruses from sugarcane and maize in China. Archives of Virology, v.147, p.1237-1246, 2002.

DENG, C.L.; WANG, W.J.; WANG, Z.Y.; JIANG, X.; CAO, Y.; ZHOU, T.; WANG, F.R.; LI, H.F.; FAN, Z.F. The genomic sequence and biological properties of Pennisetum mosaic virus, a novel monocot-infecting potyvirus. Archives of Virology, v.153, p.921-927, 2008.

DUDIENAS, C.; DUARTE, A.P.; PATERNIANI, M.E.G.Z.; RIBEIRO, J.L.; BIANCHINI, M.T.; KANTACCH, R.A.D.; CASTRO, J.L.; SILVEIRA, L.C.P.; DENUCCI, S.; SABINO JUNIOR, J.; BOLONHESI, D.; DE SORDI, G. Severidade de doenças no milho safrinha no Estado de São Paulo em 1996. In: SEMINÁRIO SOBRE A CULTURA DO MILHO SAFRINHA, 4., 1997, Assis. Anais. Campinas: IAC/CDV, 1997. p.107-115.

ESPEJEL, F.; JEFFERS, D.; NOA-CARRAZANA, J.C.; RUIZ-CASTRO, S.; SILVA-ROSALES, L. Coat protein gene sequence of a Mexican isolate of Sugarcane mosaic virus and its infectivity in maize and sugarcane plants. Archives of Virology, v.151, p.409-412, 2006.

FERNANDES, F.T.; OLIVEIRA, E. de. Principais doenças na cultura do milho. Sete Lagoas: Embrapa-CNPMS, 1997. 80p. (Embrapa-CNPMS. Circular técnica, 26).

GONÇALVES, M.C.; MAIA, I.G.; GALLETI, S.R.; FANTIN, G.M. Infecção mista pelo Sugarcane mosaic virus e Maize rayado fino virus provoca danos na cultura do milho no Estado de São Paulo. Summa Phytopathologica, v.33, p.22-26, 2007a.

GONÇALVES, M.C.; SANTOS, A.S.; MAIA, I.G.; CHAGAS, C.M.; HARAKAVA, R. Caracterização de um isolado do Sugarcane mosaic virus que quebra a resistência de variedades comerciais de cana-de-açúcar. Fitopatologia Brasileira, v.32, p.32-39, 2007 b.

HALL, T.A. BioEdit: a user-friendly biological sequence alignment editor and analysis program for Windows 95/98/NT. Nucleic Acids Symposium Series, v.41, p.95-98, 1999.

HEMA, M.; SREENIVASUlU, P.; SAVITHRI, H.S. Taxonomic position of sugarcane streak mosaic virus in the family Potyviridae. Archives of Virology, v.147, p.1997-2007, 2002.

LESEMANN, D.E.; SHUKLA, D.D.; TOSIC, M.; HUTH, W. Differentiation of the four viruses of the sugarcane mosaic virus subgroup based on cytopathology. Archives of Virology, v.5, p.353-361, 1992. Supplement.

NATIONAL CENTER FOR BIOTECHNOLOGY INFORMATION. Basic Local Alignment Search Tool - Blast. Available at: $<$ http:// blast.ncbi.nlm.nih.gov/Blast.cgi>. Accessed on: 16 May 2011a.

NATIONAL CENTER FOR BIOTECHNOLOGY INFORMATION. GenBank. Available at: <http://www.ncbi.nlm.nih.gov/genbank/>. Accessed on: 16 May 2011b.

PERERA, M.F.; FILIPPONE, M.P.; RAMALLO, C.J.; CUENYA, M.I.; GARCÍA, M.L.; PLOPER, L.D.; CASTAGNARO, A.P.
Genetic diversity among viruses associated with sugarcane mosaic disease in Tucumán, Argentina. Phytopathology, v.99, p.38-49, 2009.

PIRONE, T.P. Sugarcane mosaic virus. Surrey: Association of Applied Biologists, 1972. (AAB. Descriptions of Plant Viruses, 88).

SAMBROOK, J.; FRITCSH, E.F.; MANIATIS, T. Molecular cloning: a laboratory manual. $2^{\text {nd }}$ ed. New York: Cold spring Harbor, 1989.

SCHUELTER, A.R.; SOUZA, I.R.P. de; OLIVEIRA, E. de; GUIMARÃES, C.T. Controle genético da resistência ao mosaico-comum em linhagens de milho tropical. Revista Brasileira de Milho e Sorgo, v.2, p.103-110, 2003.

SEIFERS, D.L.; SALOMON, R.; MARIE-JEANNE, V.; ALLIOT, B.; SIGNORET, P.; HABER, S.; LOBODA, A.; ENS, W.; SHE, Y.M.; STANDING, K.G. Characterization of a novel potyvirus isolated from maize in Israel. Phytopathology, v.90, p.505-513, 2000.

SHUKLA, D.D.; FRENKEL, M.J.; MCKERN, N.M.; WARD, C.W.; JILKA, J.; TOSIC, M.; FORD, R.E. Present status of the sugarcane mosaic subgroup of potyviruses. Archives of Virolology, v.5, p.363-373, 1992. Supplement.

SHUKLA, D.D.; WARD, C.W.; BRUNT, A.A. The potyviridae. Cambridge: Cambridge University Press, 1994. 516p.

THOMPSON, J.D.; HIGGINS, D.G.; GIBSON, T.J. CLUSTAL $\mathrm{W}$ : improving the sensitivity of progressive multiple sequence alignment through sequence weighting, position-specific gap penalties and weight matrix choice. Nucleic Acids Research, v.22, p.4673-4680, 1994.

TOSIC, M.; FORD, R.E.; SHUKLA, D.D.; JILKA, J. Differentiation of Sugarcane, Maize dwarf, Johnsongrass, and Sorghum mosaic viruses based on reactions of oat and some sorghum cultivars. Plant Disease, v.74, p.549-552, 1990.

VISWANATHAN, R.; KARUPPAIAH, R.; BALAMURALIKRISHNAN, $M$. Identification of new variants of SCMV causing sugarcane mosaic in India and assessing their genetic diversity in relation to SCMV type strains. Virus Genes, v.39, p.375-386, 2009.

WANG, J.-G.; ZHENG, H.-Y.; CHEN, H.-R.; ADAMS, M.J.; CHEN, J.-P. Molecular diversities of Sugarcane mosaic virus and Sorghum mosaic virus isolates from Yunnan province, China. Journal of Phytopathology, v.158, p.427-432, 2010.

YANG, Z.N.; MIRKOV, T.E. Sequence and relationships of sugarcane mosaic and sorghum mosaic virus strains and development of RT-PCR-based-RFLPs for strain discrimination. Phytopathology, v.87, p.932-939, 1997.

ZHONG, Y.; GUO, A.; LI, C.; ZHUANG, B.; LAI, M.; WEI, C.; LUO, J.; LI, Y. Identification of a naturally occurring recombinant isolate of sugarcane mosaic virus causing maize dwarf mosaic disease. Virus Genes, v.30, p.75-83, 2005.

$\overline{\text { Recebido em } 8 \text { de dezembro de } 2010 \text { e aprovado em } 14 \text { de março de } 2011}$ 